\title{
MUSIC IN THE AMERICAN UNIVERSITY
}

\section{By J. LAWRENCE ERB}

7 HE University is an institution of learning. A considerable portion of its duty is to formulate standards and to apply those standards by means of degrees, which presumably are granted upon the completion of certain courses or after passing examinations in certain specified subjects. There arises at this point the question whether the University, as it has developed in America, is to be only an institution for the dissemination of learning, or whether it is to be also a training school for the preparation of servants of the community. The first is the more or less traditional view which is associated with the term "culture," while the second is the more democratic view which we associate with the term "service." In considering the relation of music courses and music degrees with the University it is necessary to bear in mind this distinction.

The tendency in universities of the older type, such as those of Europe and including the English as well as our own older American universities like Harvard, is toward culture courses such as are ordinarily known as theoretical. The emphasis is placed upon Harmony, Counterpoint, Canon and Fugue, History, Analysis of Form, Orchestration, and the production of exercises which are, in form at least, musical compositions. In the newer institutions, which one finds principally in the West and Middle West, the accent is placed rather upon the practical training of the musician. The theoretical courses are also offered,-in many cases perhaps offered rather than given, - and the degree of Bachelor of Music is frequently bestowed at the completion of the course, but throughout, the practical subjects are given at least equal prominence with the theoretical, and often greater. Here we have a definite line of cleavage, a different point of view between two sets of institutions of equal seriousness of purpose, and in the case of the best of either type, equally eager for the highest educational ideals and equally thorough in their training of the students. The question seems to be, which of these represents the American point of view and meets the American need.

It is not necessary here to consider those institutions which 
are Universities in name but Colleges in scope. There are many such and they are doing excellent work, but they are not concerned in this discussion.

It is evident that in any legitimate university course in music there must be considerable emphasis placed upon the theoretical subjects. No university has a right to offer less than the usual four years' course which must include Harmony, History of Music, and Esthetics (the two latter as adapted to the needs of the musician), Counterpoint, Canon and Fugue, and Analysis of Form, and every university has the duty to add, if passible, other important items such as Orchestration, Composition and more extensive courses in History of Music for the training of competent, professional historians of music, teachers of musical history and critics. It is not enough, it would seem, that these courses be offered in the cut and dried fashion which has so generally characterized them in the past history of American universities. There should be a much greater attention to the analytical study of specific compositions, and the range of such compositions to be studied ought to be wide enough to afford a reasonable acquaintance with every type of musical literature. This does not mean an exhaustive list by any means, but a representative selection which is within the scope of every well-organized University department of Music. Such a course may be called Appreciation or it may be called something else. It may be carried on with the assistance of the mechanical machines, or, as in some cases, by the use of illustrative material furnished by the professor in charge of the class or by students; but that it must be a part of a complete university musical scheme goes without saying.

The aim of this sort of course is two-fold: first to acquaint the members of the class with musical literature, and second to supply a historical and critical basis for the understanding of the compositions and incidentally to awaken the analytical and critical faculties of the students. There is no question that one of the greatest weaknesses of the American musical situation at the present time is a lack of intelligent criticism, a lack of constructive listening even among educated people and musicians of a certain class. One hears too often the statement that a certain composition is good because "I like it" and it is bad because "I do not like it." This sort of thing has kept the earnest musician helpless, subject to the whims of people who know nothing about the art but who are very positive in their opinions. For this same reason, the study of musical appreciation should be begun as far down in the school system as possible, for we need intelligent 
listeners even more than we need performers and composers, and we need them in all ranks of society. In fact, it is not likely we shall have our fair share of either performers or composers until we have a larger number of intelligent listeners.

The conduct of such an Appreciation course must produce results, that is, the study of the compositions in hand must be in detail, must be at first hand, must be intelligently directed, and must include all of the elements which ought to enter into such study, such as the historical, the structural, the technical and the critical. It is not enough simply to play or sing a composition through once or twice and then lay it aside. We have tens of thousands of people in America who are suffering with serious cases of musical dyspepsia simply because they have done too much of this sort of thing. They have listened and heard until they have no longer the power of assimilation and they have become musically blase or musical faddists. The healthy development of musical taste and culture can come only with the proper assimilation of what we hear, and assimilation can come only after analysis and digestion.

So far the practice of the older universities in this country has worked out successfully, but it is in stopping here that the younger institutions would take issue with them. They would say that such a scheme is all very well where the student has already acquired a considerable practical musical training, but that the American people will not tolerate as a musician him who cannot perform or compose acceptably. The American people, too, do not take seriously one who styles himself a musician and simply talks or writes about music but cannot "make" it, or, at any rate, never in his career was a musician in the above sense. He may be never so intelligent, never so well-informed in matters involving great research, but from the American point of view he is not a musician, but rather a historian or essayist or what not. Even the older institutions are beginning to feel the need of providing for practical musical education, and while it is often not included among the courses leading to the Bachelor's degree, opportunity is afforded for acquiring practical training, under the auspices of the institution in most cases, but at extra expense. The newer university says this plan is a humbug. If the institution is to offer the work, why not include it as a university course under strict university supervision, and why charge extra fees? It is significant that a few of the older institutions have actually made the first move in the direction of including practical music courses by allowing in connection with the Appreciation work, for the 
practical preparation of illustrative material, a certain small amount of credit toward the undergraduate degree.

This points the way to what I believe is the true function of the musical courses in an American university. Since the American university is becoming increasingly a training school,but with its culture features strongly marked,-opportunity must be offered for the training in all of its aspects under the supervision of the university faculty. Therefore, except in those few great cities where the private music schools are sufficiently well developed to take care with reasonable success of the practical musical training of students, it must be a part of the work of the university itself to furnish this practical training; and even in the large cities there must be a measure of university supervision. That too large a proportion of the time and energy of the students may be easily expended upon the practical work must be admitted; that the broad cultural phases of music have been slighted and in many cases neglected must also be admitted, but that the training in applied music may safely be left to outside teachers is a question which will be answered in the negative by practically every institution of learning west of the Alleghany mountains and by a considerable number in the East as well.

The reason for this verdict lies in the nature of the musical instruction offered in the studios and schools, with but few exceptions throughout the country. Music-teaching is a disorganized, unstandardized profession, - in fact, too often it is a business rather than a profession,-and at its best it is extreme specialization, while at its worst it is indescribable. Actually it is not music teaching at all, except as a by-product, but Piano-teaching, or Voice-culture, or some other technically specialized process with Music simply a means for demonstrating the admirable (!) results of the system (or method.) That this sort of study has educational value is not to be denied, but it is the education of the artisan rather than of the artist, for the trade rather than for the profession, producing technique rather than culture or art of a high grade. I have no quarrel with this sort of training in its place. The world must have artisans that it may have artists. But it is not the function of the university to create or develop artisans. Hence the university cannot afford to delegate any portion of its educational processes to a utilitarian or commercialized and at all times irresponsible influence. It is the policy of the American university to offer all courses, after matriculation, which are accepted toward the degree. The practice of granting degrees after successfully passing certain examinations is not 
acceptable in this country. Therefore, since Applied Music is a necessary part of the equipment of the music student it is a necessary part of the curriculum of any university offering serious musical courses, and should logically be offered without extra fees, except on the same basis as other laboratory fees.

This opens up another important problem in connection not only with university but with all music instruction,-namely the private lesson. As a matter of business, the private lesson is a gold-mine. Educationally the private lesson system, except for short terms, is both wasteful and unsatisfactory. The reaction of mind upon mind, the opportunity to study at first-hand problems other than one's own,-and to observe at first-hand virtues other than one's own,- the economy of time and effort with the consequent ability to cover a wider range,-all these and many other arguments may be advanced in favor of the class system of teaching. Private lessons should be like tutoring, for emergencies and special cases. The class system makes possible the introduction of applied music into the university upon its proper basis. Its practicability has been demonstrated by every great conservatory in Europe.

There remains a third and most important field for exploitation by the university. For lack of a better term let' us call it Community Music. Under this head would fall the various and sundry organizations of the student-body and of the community at large. These are now too often without definite connection with or intelligent supervision by the university, though owing their existence entirely to it and regarded to a great extent as representative of its musical taste, culture, and activities. Every university ought to have its Department of Community Music, designed first for service and then for instruction and propaganda, including the various phases of university extension work. Under its beneficent guidance should fall, whether officially or unofficially, all Glee Clubs, Bands, Orchestras, Choral Societies, Choirs, and any other musical organizations of whatever sort. Its function should be the organizing and purveying of musical entertainments of all kinds, not only formal (and formidable) but informal. It should be as much concerned with the Mandolin Club as with the course of Symphony Orchestra Concerts by visiting organizations, with the informal Campus and Club-house "sings" as with the Oratorio Chorus or the Grand Song Recital by Mme. Cantatrice. There is a vast amount of musical enthusiasm and energy going to seed in our American colleges and universities, just where it 
could be most easily conserved and used as a tremendous educational influence all over the land where university men and women live. Instead of lamenting because the Glee and Mandolin Clubs are musically so inferior, the wise thing would be to help them find themselves. Instead of bemoaning the fact that students sing nothing but "rag-time", which is often the only music they know, it would be well to teach them something better. Total depravity is no more a characteristic of the college student than of young men and women in the world at large, yet we take pains, through settlement work, free lectures, and recitals, and the like, to reach these latter, and then grumble because the much busier college man does not take the time and trouble to seek out what we painstakingly bring to the door of his brother.

The time was, not so long ago, when it was necessary to make strict rules, - which were difficult to enforce because of hostile or indifferent public opinion,-looking to proper attention to the physical welfare of students. To-day the overwhelmingly popular thing in all American colleges and universities is Physical Training in its Applied Form known as Athletics. Possibly a little wisdom and foresight, a little willingness to prescribe for our students what they need and then to help them like what we prescribe, may produce in a generation an enthusiasm for Music in our colleges and universities which will be as universal and overwhelming as now is exhibited only through Athletics. Who knows? In any event, a wider interest in and love for music in the country at large will be vastly accelerated by creating enthusiasm and intelligent appreciation and worthy leadership on the part of those to whom every community looks for its ideals and its leaders - our American Aristocracy, if you will,- -those to whom the state and society have granted the privilege of university or collegiate education. Therefore, every phase of musical activity should receive its due representation in the curriculum of the university or should be under the care of some member of its musical faculty. And that representation and care should be so tactful and withal so enthusiastic that the persuasion or the contagion, working upon the collective mind of the studentbody, should make music as real and vital to the students as are their most cherished collective activities. Then will each student become a propagandist for good music and a power in his community for musical uplift. Thus will follow, in the course of a few student-generations, the atmosphere for which musicians have been so long hoping, and the universal intelligence and cooperation which alone will make America a musical nation. 